\title{
Observations of mammalian feeding by Australian freshwater crocodiles (Crocodylus johnstoni) in the Kimberley region of Western Australia
}

\author{
Ruchira Somaweera ${ }^{1, *}$, David Rhind ${ }^{2}$, Stephen Reynolds ${ }^{3}$, Carla Eisemberg ${ }^{4}$, \\ Tracy Sonneman ${ }^{5}$ and David Woods ${ }^{5}$ \\ ${ }^{1}$ Ecosystem Change Ecology, CSIRO Land \& Water, Floreat, Western Australia 6014, Australia. \\ 2 School of Biological Sciences, Monash University, Clayton, Victoria 3800, Australia. \\ ${ }^{3}$ Environs Kimberley, Broome, Western Australia 6725, Australia. \\ ${ }^{4}$ Charles Darwin University, Darwin, Northern Territory 0909, Australia. \\ ${ }^{5}$ Department of Biodiversity Conservation and Attractions, West Kimberley District Office, Broome, \\ Western Australia 6725, Australia.
}

* Corresponding author: ruchira.somaweera@csiro.au

\begin{abstract}
The dietary preference of most crocodilians is generally thought to be fairly broad. However, the head morphology of slender-snouted crocodilians limits their ability to process large and complex prey. The slender-snouted Australian freshwater crocodile is known to be a dietary specialist consuming small aquatic prey, particularly aquatic arthropods and fish. Here, we report observations of predation events by Australian freshwater crocodiles on medium- and large-sized mammals in the Kimberley region of Western Australia including macropods, a large rodent and an echidna. We discuss the significance of our observations from an ecological and morphological perspective and propose that terrestrial mammalian prey may be a seasonally important prey item for some populations of freshwater crocodiles.
\end{abstract}

KEYWORDS: mammal, marsupial, monotreme, predation

\section{INTRODUCTION}

Crocodilians are opportunistic predators that capture and consume a range of prey items usually associated with or attracted to water. Prey preference of most crocodilians correlates strongly with the shape of the skull and the associated feeding structures (Pierce et al. 2008). While the general dietary niches of most crocodilians are well understood, anecdotal and opportunistic observations of complex or exceptional prey items broadens our understanding of the dietary breadth of these large predators. With males reaching a maximum total length of $\sim 3 \mathrm{~m}$, the Australian freshwater crocodile (Crocodylus johnstoni Krefft, 1873) is the smaller species of the two Australian crocodiles (the other being the estuarine crocodile $C$. porosus Schneider, 1801). They inhabit permanent and seasonal waterbodies upstream of tidal influences across the northern mainland tropics of the continent (in Western Australia (WA), Northern Territory (NT) and Queensland (QLD)), with a few populations occupying downstream estuarine areas (Cogger 2014; Webb et al. 1983). Given the smaller size and the mild temperament, attacks by this species on humans are rare (Somaweera 2011). Detailed dietary studies from seasonal waterbodies in the NT and QLD suggest that this species largely consumes invertebrates (aquatic/ terrestrial insects, crustaceans, arachnids) as hatchlings and juveniles and undergoes an ontogenetic shift in diet at $\sim 60 \mathrm{~cm}$ snout-vent length. Larger individuals predominantly feed on fish and other smaller and mostly aquatic vertebrates such as frogs (Tucker et al. 1996; Webb et al. 1982). Occasionally they take larger aquatic prey including elasmobranchs (e.g Pristis pristis (Linnaeus, 1758)), reptiles (e.g. Acrochordus arafurae McDowell, 1979, Elseya latisternum (Gray, 1867), varanid lizards), and birds (e.g. Anhinga melanogaster (Pennant, 1769), Microcarbo melanoleucos (Vieillot, 1817), Pelecanus conspicillatus Temminck, 1824)) (Webb et al. 1982; Cooper-Preston 1992; Tucker et al. 1996; Morgan et al. 2016; Somaweera, pers. obs.). 
Medium and large-bodied mammals, however, appear to be noticeably absent from the known prey item lists. This absence is likely a result of the relatively small size of adult crocodiles which makes it difficult to subdue larger terrestrial prey, and the shape of the skull which limits the capability of restraining and processing large prey. The freshwater crocodile has a long and narrow skull (longirostrine) which is suggested to be a specialisation for capturing mobile, small and aquatic prey (Busbey 1995). Longirostrine skulls generally allow for extra reach and a faster tip velocity which can benefit the capture of mobile prey. However, the structure and musculature of longirostrine skulls generally have reduced bite force and may be vulnerable to structural failure when processing large prey (i.e. shaking/twisting: Walmsley et al. 2013).

In this note, we describe opportunistic observations of C. johnstoni feeding on medium-large sized mammalian prey in the Kimberley region of Western Australia.

\section{METHODS}

Opportunistic observations were made during ongoing crocodilian ecology studies and opportunistic visits to Geikie Gorge National Park (-18.09265, 125.71027) along the Fitzroy River, and at Windjana Gorge National Park (-17.410579, 124.97440) along the Lennard River in the Kimberley region of WA. Both sites are situated within deep gorges surrounded by limestone cliffs and seasonally-arid landscapes, and contain a series of permanent pools which provide essential refuge for C. johnstoni during the dry season when the rivers cease to flow. An estimated 261 animals inhabit a $\sim 700 \mathrm{~m}$ long pool at Windjana Gorge National Park with a relative density of 326.2 animals per kilometre. An estimated 306 freshwater crocodiles inhabit the $6.8 \mathrm{~km}$ study site at Geikie Gorge National Park during

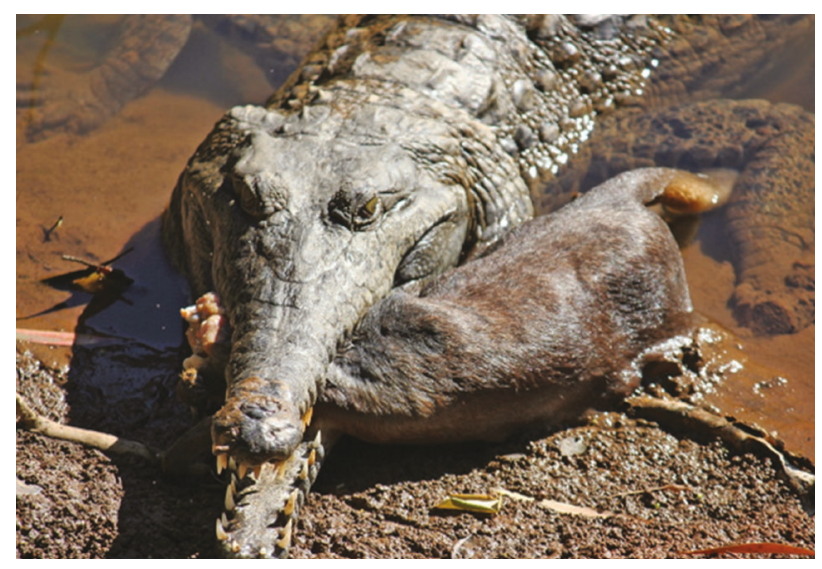

FIGURE 1 Subadult freshwater crocodile from Windjana Gorge National Park preying on most likely a large water rat (Hydromys chrysogaster) (Photo: Chris Oglethorpe). the peak dry season at a density of 44.3 animals per kilometre (Department of Biodiversity, Conservation and Attractions unpublished data). No C. porosus have been recorded from either site.

\section{RESULTS AND DISCUSSION}

In 2014, rangers from the Department of Biodiversity Conservation and Attractions (DBCA) at Geikie Gorge National Park observed two events of live captures of adult agile wallabies (Macropus agilis (Gould, 1842)) by freshwater crocodiles at the edge of the Fitzroy River. Female agile wallabies reach body weights of $16 \mathrm{~kg}$ and males $26 \mathrm{~kg}$ (Merchant 1976). They are one of the largest native mammals in the area. Both crocodiles were reported to be over $2 \mathrm{~m}$ in total length and captured the wallabies by the head, while they were drinking, after which they swam to deeper water before diving with the carcass.

Further evidence of predation on macropods was observed in October 2015 when a headless carcass of an adult macropod (body length $53 \mathrm{~cm}$, without tail) was observed at a $\sim 160 \mathrm{~m}$ long drying pool on the Lennard River. Six crocodiles, each over $1.8 \mathrm{~m}$ in total length (the largest being $2.67 \mathrm{~m}$ ) were captured from this pool. The absence of heads suggests that the interaction could have been active predation. This type of injury suggests that the attack most likely occurred while the animal was drinking and is consistent with observations of macropod predation by other species of crocodiles (Doody 2009).

In June 2010, a subadult freshwater crocodile was photographed holding a headless medium-sized mammal in its mouth at the drying pool in Lennard River at Windjana Gorge National Park (Figure 1). While the identity of the prey item is hard to ascertain, it is likely to be large water rat (Hydromys chrysogaster Geoffroy, 1804). Reaching over $35 \mathrm{~cm}$ in SVL and $1 \mathrm{~kg}$ in weight,

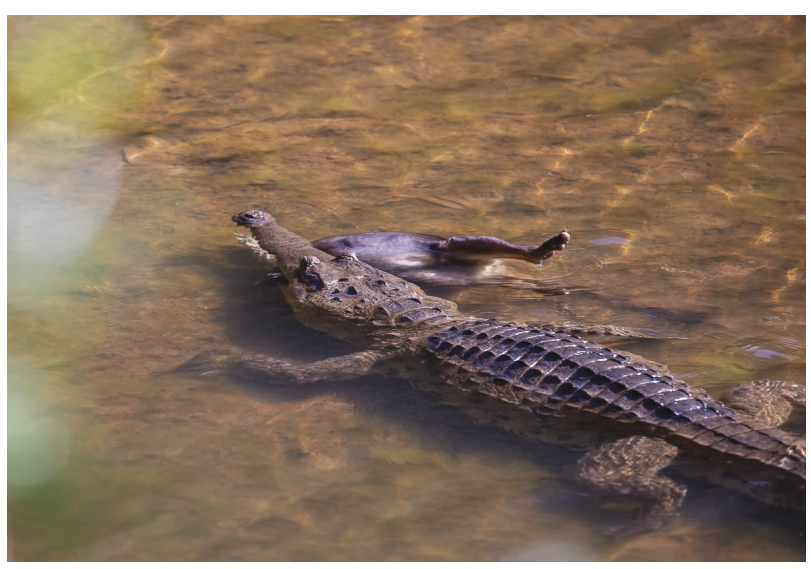

FIGURE 2 Adult freshwater crocodile from Windjana Gorge National Park swimming holding an adult short-eared rock wallaby (Petrogale brachyotis) (Photo: Cam Candy). 


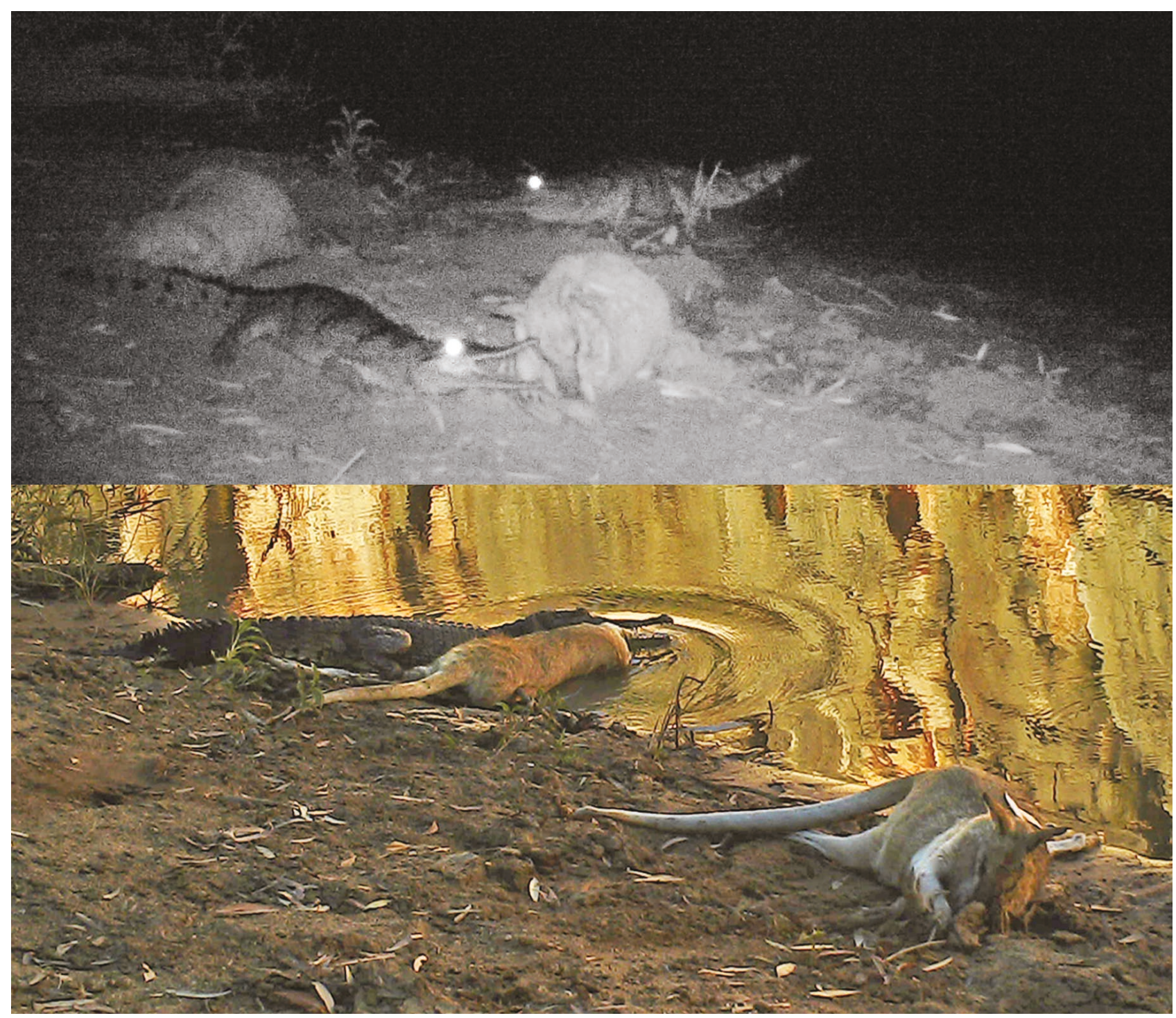

FIGURE 3 Remote camera imagery of freshwater crocodiles taking dead agile wallabies (Macropus agilis) from a bank at Geikie Gorge National Park (Photos: Ruchira Somaweera and Bruce Webber)

water rats are among the largest rodents in Australia (Van Dyck and Strahan 2008). In May 2018, a 3 m large adult crocodile was photographed swimming holding a what appeared to be an adult short-eared rock wallaby (Petrogale brachyotis (Gould, 1841)) by its head in the same pool (Figure 2). Based on the comparative size, the wallaby was estimated to be $10-15 \mathrm{~kg}$ in weight.

Given the difficulty in capturing a live hunt in images, we placed fresh (less than 6 hrs old) road-killed agile wallabies $\sim 5 \mathrm{~m}$ from the water's edge in front of remotely-triggered cameras at Geikie Gorge National Park in August 2014 and October 2016 to confirm if it was possible for freshwater crocodiles to take and dismantle large prey items. The results showed four instances of crocodiles over $1.8 \mathrm{~m}$ taking the dead agile wallabies from the river banks (Figure 3). Carcasses were then dragged into the water and dismantled by sideways thrashing of the head, both during the day and night. In one instance, a male wallaby with a head and body length of $73 \mathrm{~cm}$ and weighing $19.7 \mathrm{~kg}$ was completely consumed within 24 hrs. During this period up to three crocodiles were observed in shallow water within $\sim 10 \mathrm{~m}$ of the carcass, presumably feeding on the remains. Similar takings of dead agile wallabies and northern nail-tail wallabies (Onychogalea unguifera (Gould, 1841)) were commonly observed after a significant flood at Lake Argyle in the east Kimberley in April 2011 (R. Somaweera, pers. obs.). While these events reflect scavenging behaviour rather than predation, they prove that $C$. johnstoni is capable of handling and dismantling large terrestrial mammalian prey.

Evidence of anti-predator behaviour was observed around the pool at Windjana Gorge along the Lennard River. In particular, several noticeable 'drinking holes' were observed with scats and tracks of macropods scattered around (Figure 4). Macropods are known to dig 'drinking holes' to avoid predation risk when accessing and drinking from main water bodies 
occupied by crocodiles that could pose a threat (Steer \& Doody 2009). However, previous observations are limited to areas occupied by the much larger C. porosus, which is a well-known predator of macropods (Doody et al. 2007). Deploying the same anti-predatory tactic in waters where $C$. porosus has never been recorded, suggests that macropods do recognise the predation risk posed by freshwater crocodiles in these habitats.

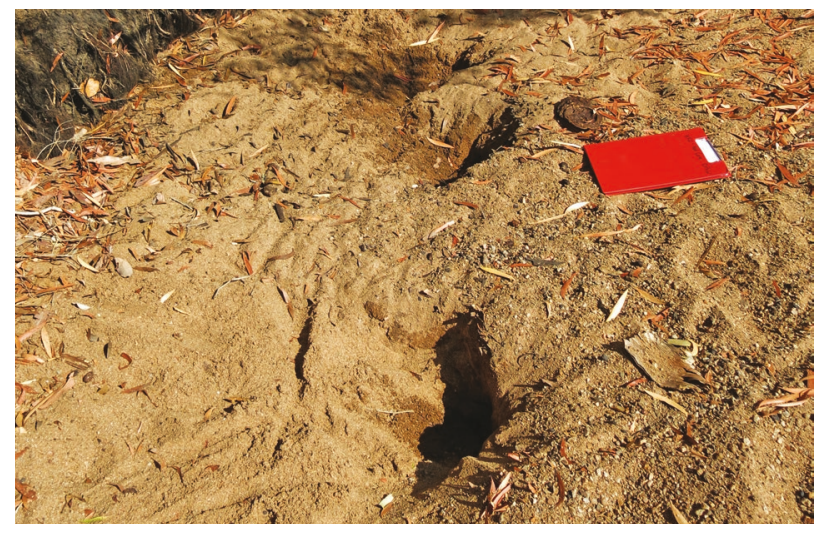

FIGURE 4

'Drinking holes' dug out by macropods at Lennard River where only Crocodylus johnstoni is found (Photo: Ruchira Somaweera).

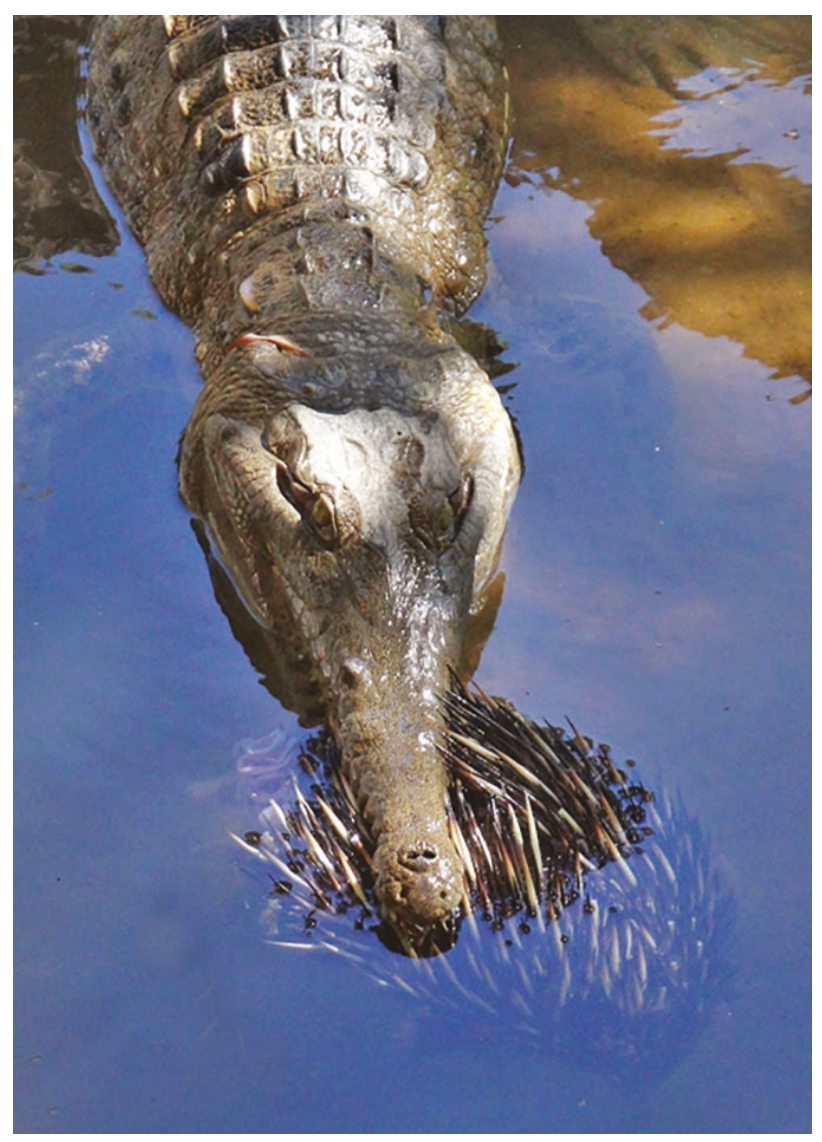

FIGURE 5 A freshwater crocodile with an adult echidna (Tachyglossus aculeata) in its mouth at Windjana Gorge National Park (Photo: Ilse Pickerd).
A complex prey item was recorded in July 2014, when an adult crocodile (estimated at $\sim 1.8-2 \mathrm{~m}$ in total length) at Windjana Gorge was observed holding an adult echidna (Tachyglossus aculeatus (Shaw, 1792)) in its mouth (Figure 5). The capture of the prey was not observed, neither was its consumption. An echidna, if consumed may present a considerable risk to the crocodile due to the defensive spines over its body. However, other instances of reptiles preying on echidnas are on record (Augee et al. 2006, Kirschner et al. 1996), as well as several other species of crocodilians preying on similar spiny prey such as porcupines (e.g. Platt et al. 2016, Samarasinghe and Alwis 2017).

The observations herein of freshwater crocodiles preying on medium and large-bodied mammalian prey provides a new perspective on the dietary ecology of this large predator. The ecological implications of such opportunistic feeding of mammalian prey by freshwater crocodiles could be significant in small isolated water bodies. During the drier months, large numbers of crocodiles congregate in remaining drying pools which also provide a vital source of water for many other animals including medium and large mammal species thus placing them at an increased risk of predation. During these periods of reduced food availability, crocodiles that could hunt the limited larger prey would have increased survival probabilities, but in the process also provide feeding opportunities to smaller animals (by generating scrap). The biomechanical implications of feeding on larger mammals with a longirostrine skull needs further investigation. Data from other longirostrine crocodilians would provide a useful insight into dietary preference of similar species. While it is highly unlikely that the skull morphology of crocodiles in these populations have adapted to allow for feeding on medium and large mammals, it provides new insight into the biomechanical constraints and limits of longirostrine skulls in crocodilians. Our observations further highlight the importance of opportunistic observations in fully understanding the ecology of cryptic predators.

\section{ACKNOWLEDGEMENTS}

We are thankful to DBCA rangers at Geikie Gorge and Windjana Gorge National Parks, Chris Oglethorpe, Cam Candy and Ilse Pickerd for sharing their observations; Bruce Webber, Paul Yeoh, the Bunuba Rangers and the volunteer field workers for their support during field work. Crocodile surveys were conducted under the research permits SF010969 and SC001387 issued to RS, TS and DW by the DBCA.

\section{REFERENCES}

Anonymous (2010) [Blog]. Our Outback Trip. Available at: https://oztrack.wordpress.com/2010/07/07/we-survived-thegibb/ [Accessed 8 Oct. 2016]. 
Augee, M.L., Gooden, B. and Musser, A. (2006). Echidna: Extraordinary Egg-laying Mammal. Collingwood, Victoria: CSIRO Publishing.

Busbey, A.B. (1995). The structural consequences of skull flattening in crocodilians. In: Thomason, J.T. (ed.). Functional morphology in vertebrate paleontology. Cambridge, Cambridge University Press.

Cogger, H.G. (2014). Reptiles and Amphibians of Australia, 7th edition. CSIRO Publishing, Melbourne.

Cooper-Preston, H. (1992). Geographic variation in the population dynamics of Crocodylus johnstoni (Krefft) in three rivers in the Northern Territory, Australia. Unpublished PhD thesis, University of New England, Armidale.

Doody, J.S. (2009). Eyes bigger than stomach: prey caching and retrieval in the Saltwater Crocodile, Crocodylus porosus. Herpetological Review 40: 26-29.

Doody, J.S., Sims, R.A. and Letnic, M. (2007). Environmental manipulation to avoid a unique predator: drinking hole excavation in the agile wallaby, Macropus agilis. Ethology 113: $128-136$.

Kirschner, A., Müller, T. and Seufer, H. (1996). Faszination Warane. Kirschner \& Seufer Verlag, Keltern-Weiler.

Merchant, J. (1976). Breeding biology of the agile wallaby, Macropus agilis (Gould) (Marsupialia: Macropodidae), in captivity. Wildlife Research 3: 93-103.

Morgan, D.L., Somaweera, R., Gleiss, A.C., Beatty, S.J. and Whitty, J.M. (2017). An upstream migration fought with danger: freshwater sawfish fending off sharks and crocodiles. Ecology 98: 1465-1467.

Pierce, S.E., Angielczyk, K.D. and Rayfield, E.J. (2008). Patterns of morphospace occupation and mechanical performance in extant crocodilian skulls: a combined geometric morphometric and finite element modelling approach. Journal of Morphology 269: 840-864.
Platt, S.G., Rainwater, T.R. and McMurry, S.T. (2016). Predatory interaction between a Morelet's crocodile (Crocodylus moreletii) and a Mexican hairy porcupine (Sphiggurus mexicanus) in Belize. Mesoamerican Herpetology 3: 474-477.

Samarasinghe, D.J.S. and Alwis, D. (2017). Crocodylus porosus (saltwater crocodile). Diet. Herpetological Review 48: 630-631.

Somaweera, R. (2011). A report of a probable unprovoked attack by an Australian freshwater crocodile at Lake Argyle in Western Australia, Australian Zoologist 35: 973-976.

Steer, D. and Doody, J.S. (2009). Dichotomies in perceived predation risk of drinking wallabies in response to predatory crocodiles. Animal Behaviour 78(5): 1071-1078.

Tucker, A.D., Limpus, C.J., McCallum, H.L. and McDonald, K.R. (1996). Ontogenetic dietary partitioning by Crocodylus johnstoni during the dry season. Copeia 1996(4): 978-988.

Van Dyck, S. and Strahan, R. (2008). The Mammals of Australia. New Holland Publishers, Sydney, Australia.

Walmsley, C.W., Smits, P.D., Quayle, M.R., McCurry, M.R., Richards, H.S., Oldfield, C.C., Wroe, S., Clausen, P.D. and McHenry, C.R. (2013). Why the long face? The mechanics of mandibular symphysis proportions in crocodiles. PLoS ONE 8(1): e53873.

Webb, G.J.W., Manolis, S.C. and Buckworth, R. (1982) Crocodylus johnstoni in the McKinlay River Area, N.T. I. Variation in the diet, and a new method of assessing the relative importance of prey. Australian Journal of Zoology 30: $877-899$.

Webb, G.J.W., Manolis, G.C. and Sack, G.C. (1983). Crocodylus johnstoni and $C$. porosus coexisting in a tidal river. Wildlife Research 10: 639-650.

MANUSCRIPT RECEIVED 19 OCTOBER 2017; ACCEPTED 20 APRIL 2018. 